\title{
Analisis kesalahan penggunaan tanda baca dan huruf miring dalam teks berita online detiknews dan tribunnews
}

\author{
Anisa Yuli Rahma Fitriani ${ }^{\text {a, 1* }}$, Laili Etika Rahmawati ${ }^{\text {b, } 2}$ \\ a Pendidikan Bahasa dan Sastra Indonesia, FKIP, Universitas Muhammadiyah Surakarta \\ b Pendidikan Bahasa dan Sastra Indonesia, FKIP, Universitas Muhammadivah Surakarta \\ 1310160064@student.ums.ac.id *; ${ }^{1}$ laili.rahmawati@ums.ac.id
}

\begin{tabular}{ll}
\hline Informasi artikel & \\
\hline Sejarah artikel: & \\
Diterima & $: 28$ November 2019 \\
Revisi & $:$ I5 April 2020 \\
Dipublikasikan & $: 30$ April 2020 \\
\hline
\end{tabular}

Kata kunci:

Kesalahan berbahasa

Berita

Berita online

\begin{abstract}
ABSTRAK
Penelitian ini bertujuan untuk (I) Mendeskripsikan bentuk kesalahan berbahasa dari segi penggunaan tanda baca dan huruf miring yang terdapat dalam teks berita online detik news dan tribun news, (2) Menjelaskan bentuk perbaikan kesalahan berbahasa dari segi penggunaan tanda baca dan huruf miring yang dominan muncul dalam teks berita online detik news dan tribun news. Penelitian ini menggunakan penelitian deskriptif dengan pendekatan kualitatif. Data dalam penelitian ini berupa kata-kata kalimat yang mengandung kesalahan berbahasa pada tanda baca dalam teks berita online detik news dan tribun news. Teknik pengumpulan data yang digunakan ialah teknik baca dan catat. teknik baca, yakni dengan membaca secara berulang-ulang isi yang terdapat dalam kolom berita online. Selanjutnya, teknik catat yang digunakan untuk menuliskan permasalahan dalam bacaan. Teknik catat yang digunakan yaitu mencatat kata atau kalimat yang merupakan bentuk kesalahan berbahasa bidang ejaan. Setelah dianalisis dan dideskripsikan berdasarkan bentuk kesalahan dalam bidang ejaan yang liputi tanda baca dan huruf miring kemudian disimpulkan dari perbaikan kalimat tersebut. Hasil penelitian menunjukan bahwa analisis kesalahan ejaan yang berupa tanda baca dan huruf miring terdapat I I kesalahan dari dua berita online detiknews dan tribunnews.
\end{abstract}

Key word:

Language errors

News

Online news

\begin{abstract}
This study aims to (I) describe the form of language errors in terms of the use of punctuation and italics contained in the online news text detik news and news stands, (2) Explain the form of language errors in terms of the use of punctuation and dominant italics appear in online news text seconds news and news stands. This research uses descriptive research with a qualitative approach. The data in this research are sentences containing language errors in punctuation in online news text detik news and news stands. Data collection techniques used are reading and note-taking techniques. reading techniques, namely by reading repeatedly the contents contained in the online news column. Next, note-taking techniques are used to write down problems in reading. The note taking technique used is to write down words or sentences which are forms of spelling mistakes in the language. After being analyzed and described based on the form of errors in the spelling fields which include punctuation and italics, then it is concluded from the improvement of the sentence. The results showed that the analysis of spelling errors in the form of punctuation and italics contained II errors from two online news detiknews and tribunnews.
\end{abstract}

\section{Pendahuluan}

Berita menjadi salah satu peranan penting dalam masyarakat dengan adanya berita kita dapat mengetetahui semua informasi. Berita pada umumya hanya dibuat versi cetaknya. Tetapi, berita saat ini sudah berkembang luas. Seperti berita online yang saat ini mudah diakses menggunakan jaringan internet dan didapatkan dimana pun kita berada. Kehadiran internet saat ini yang menyediakan berbagai ragam
Copyright (C) 2018 Universitas Ahmad Dahlan. All Right Reserved informasi dan berita lambat laun mulai mengalahkan kepopuleran koran. Bahkan banyak situs berita di internet menyajikan berita dengan cepat dan tanpa memungut biaya. Berita cetak atau koran mudah sekali di dapatkan dan bentuk koran biasanya dicetak di kertas buram dengan harga ekonomis tidak menguras kantong. Proses penyajian berita dapat dilakukan secara langsung. Masyarakat mudah sekali mendapatkan informasi yang terdapat pada surat 
kabar atau berita online (Rahmawati Nur \& Didah, 2018). Menurut (Alber, 2018:56) dalam tabloid pentingnya menggunkan kosakata baku yang mengacu pada Pedoman Umum Ejaan Bahasa Indonesia (PEUBI).

Berita yang ada dalam media massa menjadi suatu cara untuk menciptakan suatu realitas yang diinginkan mengenai peristiwa atau orang yang dilaporkan. Oleh karena itu proses seleksi dan reproduksi, berita surat kabar sebenarnya merupakan laporan peristiwa yang artifisial atau buatan, tetapi tidak dapat diklaim sebagai objektif oleh surat kabar untuk mencapai tujuan-tujuan ideologo dan bisnis dari surat kabar tersebut (Sihobing, 2017). Berita berisi mengenai informasi-informasi terbaru yang berada di sekitar kita dan disajikan dengan cara ditulis. Media juga menjadi sarana untuk penyebaran ideologi penguasaan dan sebuah kontrol publik. Media juga menjadi alat untuk membangun budaya yang dominan (Suwartini, 2014).

Penulisan dalam berita online sama dengan koran. Hanya saja terdapat perbedaan dalam proses pemuatannya, dimana berita online menggunakan internet. Koran atau media cetak merupakan media yang tidak hanya disajikan dalam pemberitaan saja akan tetapi mempunyai dan ideologi tertentu (Yosi, 20I4). Tampilan awal ketika dibuka yang terdapat dalam berita online hanya muncul judul berita dan ketika ingin membaca berita tersebut harus mengeklik pada tampilan layar berita. Koran tidak kalah dengan berita online. hanya saja, berita online lebih cepat update atau akses sedangkan koran harus melewati tahapan terlebih dahulu seperti dicetak. Bahasa dalam berita cetak maupun berita online tidak hanya membahas mengenai politik, tetapi juga membahas mengenai semangat nasionalisme (Sari Rika Dewi, Fadhilah \& Nucifera, 2019:26)

Berita online banyak terbagi menjadi berbagai beberapa yang salah satunya artikel yang dimuat untuk menyampaikan informasi seperti kejahatan, korupsi, bencana alam, pembunuhan dan lain-lain (Sutrisna, 2017). Berita yang terdapat dalam detik news dan tribun news sangatlah menarik mulai dari penyajian berita. Penyajian berita tribun news identik dengan gambar-gambar yang besar, berita singkat, dan menarik. Sedangkan detik news dalam mengakses berita lebih mudah, dan bisa diakses kapanpun tampilan menarik dan lebih banyak tulisannya dari pada gambar. Penggunaan media massa seperti berita digunakan sebagai penyampaian sebuah pesan (Prihantoro \& Fitriani, 20I5).

Penyajian dalam berita masih banyak terjadi kesalahan dalam penulisan hampir semua berita online dan cetak. Seperti berita yang terdapat dalam detik news dan tribun news. Biasanya kesalahan yang terdapat dalam berita online ini kurang teliti dalam penyuntingan sehingga kesalahan mudah terjadi. Kesalahan terdapat pada ejaan. Kesalahan dalam bidang ejaan seperti penggunaan huruf kapital, tanda hubung, tanda titik, tanda koma, kesalahan petik tunggal, tanda kurung, tanda tanda titik dua, tanda seru. Dalam berita tribun news masih banyak kesalahan yang terjadi dalam berita yang disajikan berbeda dengan detik news hanya beberapa tulisan dalam bacaan yang terdapat kesalahan.

Dalam penulisan bahasa Indonesia sebaiknnya lebih diperhatikan lagi agar terlihat baik dan benar dalam penulisan. Hal yang harus diperhatikan adalah kaidah kebahasaan dan pemilihan kata yang tepat agar pembaca tidak mengalami kesulitan saat membaca. Penggunaan bahasa yang mengikuti kaidah yang dianggap baku merupakan pemakaian bahasa dengan benar. Dengan pengggunaan bahasa yang baik dan benar akan bermanfaat bagi seluruh masyarakat, pelajar dan khususnya pembaca berita.

Penelitian ini menganalisis mengenai analisis kesalahan berbahasa yang terdapat dalam berita online detik news dan tribun news. Analisis kesalahan berbahasa berhubungan erat dengan linguistik. Secara umum linguistik memiliki arti ilmu yang mempelajari sebuah bahasa yang meliputi bidag fonologi, morfologi, sintaksis dan semantik (Rahmawati, Kartikasari, \& Sukoco, 20I4).

Kesalahan meliputi kesalahan dari segi ejaan. Kesalahan ejaan yaitu penggunaan tanda baca dalam tulisan atau berita. Dalam penempatan pada posisi tanda baca salah maka, makna yang terkandung dalam tulisan tersebut berbeda dengan maksud atau tujuannya (Arizona \& Rusmito, 2016). Menurut Lantuba, Yanis Men, (2017:107) Ejaan dalam penulisan sangatlah pengting. Kesalahan ejaan bisa menimbulkan kegagalam pembaca, kegagalan disebabakan ketidakpaham tulisan yang di dilakukan oleh penulis. Ejaan merupakan lambang bunyi ujaran, menempatkan tanda titik, tanda koma, tanda titik koma, tanda hubung, tanda seru, tanda pisah, tanda tanya dang garis miring dalam sebuah kata (Sasongko Dwi Sempu, 2018:29)

Kaitanya mengenai kesalahan berbahasa membedakan antara istilah kesalahan berbahasa (eror) dengan kekeliruan berbahasa (mistake). Istilah tersebut penyimpangan yang bersifat sistematis, konsisten, da menggambarkan kemampuan seorang peserta didik pada tahap tertentu. Sedangkan kekeliruan merupakan hal menyimpang yang tidak sistematis, yang berada pada wilayah performasi atau perilaku berbahasa. Akan tetapi, kesalahan berbahasa yang dibuat oleh siswa harus dikurangi. Kesalahann berbahasa biasanya terdapat dalam media cetak yaitu 
surat kabar yang berbentuk (Markhamah \& Sabardila, 2010)

Analisis kesalahan berbahasa menurut Usha \& Kader (2016) pendekatan linguistik terapan yang digunakan untuk mengidentifikasikan bidang-bidang yang sulit bagi pelajar bahasa kedua. Kesalahan dalam berbahasa terjadi tidak hanya di berita. Hampir keseluruhan berita mengalami kesalahan dalam ejaan ,karena berita merupakan media perantaran untuk menghubungkan berita kepada masyarakat (Winata, 2019:I 17). Menurut Ariyanti (2019:14) Analisis kesalahan berbahasa adalah proses dimana seorang peneliti menemukan bentuk kesalahan berbahasa dengan cara mengumpulkan data keseluruhan mengenai kesalahan dengan menggunakan teori-teori terdahulu yang sudah ada.

Analisis kesalahan berbahasa sejalan penelitian yang dilakukan oleh peneliti lain. Yudha (20I4) Analisis Keslahan Berbahasa Dalam Karangan Bahasa Indonesia Siswa Kelas XI SMK Negeri Rembang Kabupaten Pasurun Tahun Pelajaran 2013/20I4. Penelitian Nisa (2018) meneliti tentang analisis kesalahan berbahasa pada berita dalam media surat kabar sinar Indonesia baru. Penelitian Faisah (2018) meneliti tentang analisis kesalahan berbahasa Indonesia dalam surat menyirat di kantor kelurahan layana indah. Penelitian yang sejalan Ariani (2019) Analisis Kesalahan Ejaan Dalam Karangan Siswa Pada Mata Pelajaran Bahasa Indonesia Kelas III 2 Mojorum Kecamatam Gondang Kabupaten Tulungagung Tahun Ajaran 2018/2019. Penelitian dari Santoso dan Sabardila, Atiqa (2018) meneliti analisis kesalahan berbahasa pidato mahasiswa MPB-UMS yang memerankan diri menjadi calon kepala daerah kabupaten blora. Penelitian yang sama Salam Sucipto, Sumardi (2016) Analisis kesalahan penggunaan tanda baca tanya dan tanda baca titik pada teks dialog siswa. Penelitian sejalan dengan Septina Lisdayanti (2019) Kesalahan Penggunaan Ejaan Pada Informasi Layanan Niaga Di Kota Bengkulu.

Penelitian yang sama dari Kurniasari, Nia Andrianti \& Isnaini (2018) meneliti tentang analisis kesalahan ejaan pada salah satu judul berita "isu tka digoreng menjelang pilpres" pada surat kabar tribun jabar edisi 25 april 2018. Penelitian dari (Fauzi, Bastanul. Rizal, Syaiful.Rohman, 2019) meneliti tentang analisis kesalahan ejaan dan kalimat dalam skripsi mahasiswa universitas brawijaya sebagai dasar penentuan strategi, tujuan, dan bahan ajar mata kuliah bahasa indonesia di universitas brawijaya. Penelitian dari N, Km, Sartika, Rasna, \& Sudiara (20I4) analisis kesalahan bahasa indonesia pada esai mahasiswa jurusan pendidikan bahasa dan sastra indonesia: sebuah kajian ejaan, diksi, dan struktur. Penelitian yang sejalan Nisa, Khoirun (2017) Kesalahan Penggunaan Bahasa Indonesia Dalam Teks Terjemahan Mahasiswa. Reza Qhadafi (2018) Analisis Kesalahan Penulisan Ejaan yang Disempurnakan dalam Teks Negosiasi Siswa SMA Negeri 3 Palu. Perbedaan dalam penelitian ini pada analisis kesalahan dalam teks berita online detik news dan tribun news yang berfokus pada segi ejaan.

\section{Metode}

Metode penelitian digunakan sebagai alat bantu peneliti dalam memecahkan permasalahan yang diajukan dalam penelitian ini. Penelitian ini menggunakan penelitian kualitatif dengan metode deskriptif. Sumber data dalam berita online detik news dan tribun news. Data dalam penelitian ini berupa kata-kata, kalimat yang mengandung kesalahan berbahasa pada bidang ejaan. Data dikumpulkan dengan teknik baca dan catat. Analisis data dalam artikel ini untuk menggali permasalahan yang akan dikaji. Seperti kajian kesalahan berbahasa segi ejaan yang meliputi tanda baca dan huruf miring. Setelah data terkumpul langkah selanjutnya adalah menganalisis data dengan kajian kesalahan berbahasa bidang ejaan, pada teks berita online detiknews, tribunnews.

\section{Hasil dan pembahasan}

\section{Kesalahan Tanda Baca Dan Huruf Miring}

Kesalahan berbahasa dalam bidang ejaan meliputi kesalahan penggunaan huruf kapital, penggunaan tanda koma, penggunaan tanda hubung, penggunaan tanda titik (Manaf, 2013).

\section{Data I: Tribunnews}

Analisis Kesalahan Berbahasa Pada Berita "Fakta Baru Anak Bunuh Ayah di Tegal, Kubur Jasad di Septic Tank \& Dicor, Pelaku Diduga Gangguan Jiwa”.

I. Kesalahan ejaan pada penggunaan tanda hubung.

Kutipan berita : "Informasi itu disampaikan Kapolsek Warureja Iptu Nugroho Santoso, yang menyatakan pelaku kerap bolak balik ke rumah sakit untuk pemeriksaan kejiwaan".

Kesalahan : Informasi itu disampaikan Kapolsek Warureja Iptu Nugroho Santoso, yang menyatakan pelaku kerap bolak balik ke rumah sakit untuk pemeriksaan kejiwaan.

Perbaikan : setelah kata kerap seharusnya menggunakan tanda hubung (bolak-balik) yang berguna untuk menyambung unsur kata ulang. Kalimat yang tepat Informasi itu disampaikan Kapolsek Warureja Iptu Nugroho Santoso, yang 
menyatakan pelaku kerap bolak-balik ke rumah sakit untuk pemeriksaan kejiwaan.

2. Kesalahan ejaan pada penggunaan tanda hubung

Kutipan berita : "Pelaku itu diduga mengalami gangguan jiwa. Bolak balik ke rumah sakit untuk periksa kejiwaan," kata Nugroho, saat mengamankan jalannya autopsi jenazah Rahadi oleh Tim DVI Polda Jateng, di makam desa setempat, Kamis (31/10/2019).

Kesalahan : "Pelaku itu diduga mengalami gangguan jiwa. Bolak balik ke rumah sakit untuk periksa kejiwaan," kata Nugroho, saat mengamankan jalannya autopsi jenazah Rahadi oleh Tim DVI Polda Jateng, di makam desa setempat, Kamis (31/10/2019).

Perbaikan : setelah kata gangguan jiwa. Seharusnya menggunakan tanda hubung (bolak-balik) yang berguna untuk menyambung unsur kata ulang.

3. Kesalahan ejaan pada penggunaan tanda titik Kutipan berita : Senada disampaikan Kepala Desa Kendayakan, Rasiun. Informasi dari tetangga sekitar dan keluarga, kata dia, pelaku pernah berobat sampai tiga kali di RS Mitra Siaga Tegal.

Kesalahan : Senada disampaikan Kepala Desa Kendayakan, Rasiun. Informasi dari tetangga sekitar dan keluarga, kata dia, pelaku pernah berobat sampai tiga kali di RS Mitra Siaga Tegal.

Perbaikan : kata keluarga seharusnya menggunakan tanda titik agar lebih memperjelas tempat pemberhentian tanda tersebut, tidak seluruhnya menggunakan tanda koma.

4. Kesalaha ejaan pada penggunaan tanda titik Kutipan berita : "Kalau diajak komunikasi nyambung kaya orang normal," kata dia

Kesalahan: "Kalau diajak komunikasi nyambung kaya orang normal," kata dia

Perbaikan : kata dia diakhir kalimat seharusnya menggunakan tanda titik agar lebih memperjelas tempat pemberhentian tanda tersebut.

5. Kesalahan ejaan pada penggunaan huruf capital

Kutipan berita : Senada disampaikan Kepala Desa Kendayakan, Rasiun. Informasi dari tetangga sekitar dan keluarga, kata dia, pelaku pernah berobat sampai tiga kali di RS Mitra Siaga Tegal.

Kesalahan : Senada disampaikan Kepala Desa Kendayakan, Rasiun. Informasi dari tetangga sekitar dan keluarga, kata dia, pelaku pernah berobat sampai tiga kali di RS Mitra Siaga Tegal.

Perbaikan : setelah kata kelurga seharusnya (kata dia) menggunaka huruf kapital. Karena dalam kata keluarga diakhiri dengan tanda titik.

6. Kesalahan ejaan pada penggunaan tanda koma
Kutipan berita : Namun, jika tidak, petugas akan mengambil tindakan tegas kepada dua orang buronan tersebut.

Kesalahan : Namun, jika tidak, petugas akan mengambil tindakan tegas kepada dua orang buronan tersebut.

Perbaikan : kata jika tidak seharusnya tidak menggunakan tanda koma.

Data 2: Tribunnews

Analisis Kesalahan Berbahasa Pada Berita Uang Ibu PNS PUPR yang Tewas Dicor Digunakan Pelaku Foya-foya Karaoke dan Sewa 2 Wanita.

I. Kesalahan ejaan pada penggunaan huruf kapital

Kutipan berita : Apriyanita, PNS Kementerian PU. dan pengangkutan jenazah pns yang dicor (Tribun Sumsel/ Shinta Dwi Anggraini)

Kesalahan : Apriyanita, PNS Kementerian PU. dan pengangkutan jenazah pns yang dicor (Tribun Sumsel/ Shinta Dwi Anggraini)

Perbaikan : setelah kata PU. Seharusnya kata dan menggunakan huruf kapital. Karena dalam kata PU diakhiri tanda titik dan kata PNS harus menggunakan huruf kapital karena singakatan gelar.

2. Kesalahan ejaan pada penggunaan tanda koma

Kutipan berita : Nopi lalu mengajak dua rekanny,a Amir dan Ilyas (26) untuk ikut beraksi.

Kesalahan : Nopi lalu mengajak dua rekanny,a Amir dan Ilyas (26) untuk ikut beraksi.

Perbaikan : dalam penulisan kata rekannya seharusnya kata ny,a tidak disisipi tanda koma.

Data 3: Tribunnews

Ponakan Pembunuh Paman Jalani Rekontruksi, Mengaku Kesal Saat Dimarahi Sewaktu Bermain Game Online.

I. Kesalahan penggunaan tanda titik.

Kutipan berita : Ali mengatakan, tak ada fakta baru yang ditemukan dalam. adegan rekonstruksi ini.

Kesalahan: Ali mengatakan, tak ada fakta baru yang ditemukan dalam. adegan rekonstruksi ini.

Perbaikan: pada kata dalam seharusya tidak diakhiri dengan tanda titik. Karena bukan akhir dari kalimat. Kalimat berbunyi Ali mengatakan, tak ada fakta baru yang ditemukan dalam adegan rekontruksi ini.

2. Kesalahan penggunaan huruf miring.

Kutipan berita : Terkait motif pelaku, Ali menyebut berdasarkan hasil BAP, AM mengaku kesal lantaran ia dimarahi pelaku sewaktu sedang bermain game online.

Kesalahan: Terkait motif pelaku, Ali menyebut berdasarkan hasil BAP, AM mengaku kesal lantaran ia dimarahi pelaku sewaktu sedang bermain game online. 
Perbaikan: setelah kata bermain seharusnya game online menggunakan huruf miring yang merupakan bahasa asing. Kalimat berbunyi terkait motif pelaku, Ali menyebut berdasarkan hasil BAP, AM mengaku kesal lantaran ia dimarahi pelaku sewaktu sedang bermain game online.

\section{Data 4: Tribunnews}

Awalnya Cuma Curhat Dengan Bos Suami: Istri Lalu Selingkuh Dengan Bos Suami \& Rencanakan Bunuh Suami.

Kutipan berita: Teman curhatnya ini bernama BHS (33) ternyata adalah bos suaminya, VT, dikantor.

I. Kesalahan ejaan pada penggunaan tanda koma

Kesalahan : Teman curhatnya ini berama BHS (33) ternyata adalah bos suaminya, VT, dikantor.

Perbaikan : terlalu banyak menggunakan tanda koma dalam satu kalimat. Kalimat perbaikannya teman curhatnya ini bernama BHS (33) ternyata adalah bos suaminya VT dikantor.

2. Kesalahan ejaa pada penggunaan tanda koma Kutipan berita: YL dan BHS yang menjalin hubungan terlarang, berselingkuh, kemudian merencanakan pembunuhan terhadap VT, suami sah YL.

Kesalahan: YL dan BHS yang menjalin hubungan terlarang, berselingkuh, kemudian merencanakan pembunuhan terhadap VT, suami sah YL.

Perbaikan: terlalu banyak menggunakan tanda koma dalam satu kalimat. Kalimat perbaikannya YL dan BHS yang menjalin hubungan terlarang berselingkuh, kemudian merencanakan pembunuhan terhadap VT, suami sah YL.

3. Kesalahan ejaann penggunaan tanda koma Kutipan berita: Di dalam mobil itu, ada juga BK, yang berperan sebagai eksekutor.

Kesalahan: Di dalam mobil itu, ada juga BK, yang berperan sebagai eksekutor.

Perbaikan: terlalu banyak menggunakan tanda koma dalam satu kalimat. Kalimat perbaikannya. Di dalam mobil itu ada juga BK, yang berperan sebagai eksekutor.

\section{Data 5: Tribunnews}

Duel Dengan Suami Mantan Istri, Yadi Dolar Tewas Mengenaskan Dengan Tangan Terputus

I. Kesalahan penggunaan huruf kapital

Kutipan berita: Kabar adanya Kejadian perkelahian hingga tangan korban putus dan meninggal dunia ini cepat menyebar.

Kesalahan: Kabar adanya Kejadian perkelahian hingga tangan korban putus dan meninggal dunia ini cepat menyebar.

Perbaikan: kata kejadian seharusnya tidak diawali menggunakan huruf kapital karena kata sebelumnya tidak ada tanda titik. Kalimat berbuyi " Kabar adanya kejadian perkelahian hingga tangan korban putus dan meninggal dunia ini cepat menyebar".

2. Kesalahan penggunaan tanda koma

Kutipan berita: Suryadi diketahui mendobrak pintu samping dengan kaki kanannya, namun saat kakiya berhasil mendobrak salah satu pilar pintu, kaki korban langsung disambut sabetan parang dari arah pelaku yanng berinisial $\mathrm{Y}$ alias $\mathrm{U}$.

Kesalahan: Suryadi diketahui mendobrak pintu samping dengan kaki kanannya, namun saat kakiya berhasil mendobrak salah satu pilar pintu, kaki korban langsung disambut sabetan parang dari arah pelaku yanng berinisial $\mathrm{Y}$ alias $\mathrm{U}$.

Perbaikan: Suryadi diketahui mendobrak pintu samping dengan kaki kanannya, namun saat kakiya berhasil mendobrak salah satu pilar pintu kaki korban langsung disambut sabetan parang dari arah pelaku yanng berinisial $\mathrm{Y}$ alias U. Setelah kata pitu seharusnya tidak menggunakan tanda koma.

3. Kesalahan penggunaan tanda koma

Kutipan berita: Diketahui, menurut informasi warga setempat, Suryadi saat itu mendatangi rumah mantan istrinya, bernama Wati di kawasan Jalan Martapura Lama Komplek Antasari Perdana RT I6, Kecamatan Sungai Tabuk, Kabupaten Banjar.

Kesalahan: Diketahui, menurut informasi warga setempat, Suryadi saat itu mendatangi rumah mantan istrinya, bernama Wati di kawasan Jalan Martapura Lama Komplek Antasari Perdana RT I6, Kecamatan Sungai Tabuk, Kabupaten Banjar.

Kesalahan: terlalu banyak menggunakan tanda koma dalam satu kalimat. Seharusnya, setelah kata istrinya tdak meggunakan tada koma. Kalimat berbuyi "Diketahui, menurut informasi warga setempat, Suryadi saat itu mendatangi rumah mantan istrinya bernama Wati di kawasan Jalan Martapura Lama Komplek Antasari Perdana RT I6, Kecamatan Sungai Tabuk, Kabupaten Banjar”.

\section{Data I: Detiknews}

Analisis Kesalahan Berbahasa Pada Berita "Rektor Tunggu Salinan Putusan untuk Pecat Dosen UNM Pembunuh Zulaiha”.

I. Kesalahan penggunaan tanda titik

Kutipan berita : "Rektor UNM Prof Husain Syam yang dikonfirmasi detikcom, mengatakan, pihaknya menunggu salinan putusan Pengadilan Negeri (PN) Sungguminasa, sebelum memberhentikan Wahyu dari statusnya sebagai dosen UNM".

Kesalahan: Rektor UNM Prof Husain Syam yang dikonfirmasi detikcom, mengatakan, pihaknya menunggu salinan putusan Pengadilan Negeri (PN) Sungguminasa, sebelum memberhentikan Wahyu dari statusnya sebagai dosen UNM.

Perbaikan: setelah kata Prof seharusnya diikuti tanda titik yang merupakan nama gelar. 


\section{Data 2: Detiknews}

Analisis Kesalahan Berbahasa Pada Berita "Setahun Pembunuhan Jamal Khashoggi, Dalang Pembunuhan Masih Bebas".

1. Kesalahan penggunaan huruf miring.

Kutipan berita : "Tapi tokoh-tokoh kunci seperti alQahtani luput dari penyelidikan karena tidak masuk daftar tersangka. Intelijen Turki mengatakan, alQahtani terhubung via Skype dengan tim di konsulat Istanbul, ketika Khashoggi diinterogasi dan akhirnya tubuhnya dipotong-potong".

Kesalahan: Tapi tokoh-tokoh kunci seperti alQahtani luput dari penyelidikan karena tidak masuk daftar tersangka. Intelijen Turki mengatakan, alQahtani terhubung via Skype dengan tim di konsulat Istanbul, ketika Khashoggi diinterogasi dan akhirnya tubuhnya dipotong-potong.

Perbaikan: setelah kata via seharusnya Skype menggunakan huruf miring yang merupakan bahasa asing.

2. Kesalahan penggunaan huruf miring

Kutipan berita : "Presiden Joko Widodo memberi sambutan hangat kepada Mohammed bin Salman ketika berkunjung ke Arab Saudi April lalu, karena Putra Mahkota Arab Saudi itu menjanjikan "investasi besar" di Indonesia, Jokowi bahkan membuat vlog bersama Mohammed bin Salman”.

Kesalahan: Presiden Joko Widodo memberi sambutan hangat kepada Mohammed bin Salman ketika berkunjung ke Arab Saudi April lalu, karena Putra Mahkota Arab Saudi itu menjanjikan "investasi besar" di Indonesia, Jokowi bahkan membuat vlog bersama Mohammed bin Salman.

Perbaikan: kata vlog menggunakan huruf miring yang merupakan bahasa asing.

\section{Data 3: Detiknews}

I Pengusaha dan 5 Pembunuh Bayaran Dibui karena 'Outsourcing' Pembunuhan.

I. Kesalahan penggunaan huruf miring

Kutipan berita : "Dalam kasus yang tidak biasa ini, lima pembunuh bayaran_melakukan 'outsourcing' secara berantai terhadap perintah pembunuhan yang diberikan seorang pengusaha lokal untuk rival bisnisnya".

Kesalahan: Dalam kasus yang tidak biasa ini, lima pembunuh bayaran_melakukan 'outsourcing' secara berantai terhadap perintah pembunuhan yang diberikan seorang pengusaha lokal untuk rival bisnisnya.

Perbaikan : setelah kata melakukan seharusnya outsourcing menggunakan huruf miring yang merupakan bahasa asing.

2. Kesalahan penggunaan huruf miring
Kutipan berita : "Dalam kasus ini, sejumlah pembunuh bayaran melakukan 'outsourcing' yakni dengan meneruskan perintah"

Kesalahan: Dalam kasus ini, sejumlah pembunuh bayaran melakukan 'outsourcing' yakni dengan meneruskan perintah

Perbaikan: setelah kata melakukan seharusnya outsourcing menggunakan huruf miring yang merupakan bahasa asing.

3. Kesalahan penggunaan tanda petik tunggal Kutipan berita: "Wei sepakat dengan tawaran Ling. Sejumlah foto diambil untuk menunjukkan Wei diikat dan disekap sebelum dibunuh. Ling kemudian melaporkan 'kesuksesannya' menjalankan tugas pembunuhan itu, hingga kabar itu sampai ke Tan yang memerintahkan pembunuhan".

Kesalahan: Wei sepakat dengan tawaran Ling. Sejumlah foto diambil untuk menunjukkan Wei diikat dan disekap sebelum dibunuh. Ling kemudian melaporkan 'kesuksesannya' menjalankan tugas pembunuhan itu, hingga kabar itu sampai ke Tan yang memerintahkan pembunuhan.

Perbaikan: kata kesuksesannya tidak menggunakan tanda petik tunggal karena, tidak ada petikan lainnnya yang mengapit. Kalimat berbunyi Wei diikat dan disekap sebelum dibunuh. Ling kemudian melaporkan kesuksesannya menjalankan tugas pembunuhan itu, hingga kabar itu sampai ke Tan yang memerintahkan pembunuhan.

4. Kesalahan penggunaan huruf miring Kutipan berita: "Bahkan para pembunuh di China memahami pentingnya subkontrak dalam pekerjaan mereka," tulis seorang pengguna Weibo, semacam Twitter di China.”Inilah sifat asli bisnis," tulis pengguna Weibo lainnya.

Kesalahan: : "Bahkan para pembunuh di China memahami pentingnya subkontrak dalam pekerjaan mereka," tulis seorang pengguna Weibo, semacam Twitter di China."Inilah sifat asli bisnis," tulis pengguna Weibo lainnya. Perbaikan: setelah kata semacam seharusya kata Twitter menggunakan huruf miring. Kalimat berbunyi "Bahkan para pembunuh di China memahami pentingnya subkontrak dalam pekerjaan mereka," tulis seorang pengguna Weibo, semacam Twitter di China.”Inilah sifat asli bisnis," tulis pengguna Weibo lainnya.

Data 3: Detiknews

Napi Kasus Pembunuhan Taruna Nusantara Daftar Kuliah Disoal, Ini Kata Kalapas

I. Kesalahan penggunnaan tanda pisah

Kutipan berita: Pengajuan untuk kursus di luar lingkungan LPKA-yang dulu disebut Lapas 
Anak-disebut Lingga sudah melalui sidang Tim Pengamat Permasyaraktan (TPP) pada 23 Juli 2019. Kesalahan: Pengajuan untuk kursus di luar lingkungan LPKA-yang dulu disebut Lapas Anak-disebut Lingga sudah melalui sidang Tim Pengamat Permasyaraktan (TPP) pada 23 Juli 20I

Perbaikan: setelah kata LPKA_-dan Anak seharusya tidak meggunakan tanda pisah karena kata tersebut sudah jelas. Kalimat perbaikannya "Pengajuan untuk kursus di luar lingkungan LPK yang dulu disebut Lapas Anak. disebut Lingga sudah melalui sidang Tim Pengamat Permasyaraktan (TPP) pada 23 Juli 2019".

Data 4: Detiknews

Pengakuan Ibu Muda di Bandung yang Membunuh Bayinya, Dapat Bisikan Gaib Belum Siap Mengurus Anak.

I. Kesalahan penggunaan tanda titik koma

Kutipan berita: "\&Irm; Iya, saat ini sudah diamankan dan sedang diperiksa untuk kepentingan penyidik. Ibunya berinisial Fm (28)," ujar Kapolrestabes.

Kesalahan: "\&Irm; Iya, saat ini sudah diamankan dan sedang diperiksa untuk kepentingan penyidik. Ibunya berinisial Fm (28)," ujar Kapolrestabes.

Perbaikan: setelah kata Irm seharusnya tidak menggunakan tanda titik koma. Kalimat berbunyi $\&$ "Iya, saat ini diamankan dan sedang diperiksa untuk kepentingan penyidik. Ibunya berinisial Fm (28)," ujar Kapolrestabes.

2. Kesalahan penggunaan huruf miring

Kutipan berita: Hanya saja, dugaan awal, sang ibu yang baru melahirkan anak pertamanya itu mengalami baby blues syndrome.

Kesalahan: Hanya saja, dugaan awal, sang ibu yang baru melahirkan anak pertamanya itu mengalami baby blues syndrome.

Perbaikan: Baby blues syndrome seharusnya menggunakan huruf miring karena merupakan ungkapan asing. Kalimatnya berbunyi, Hanya saja, dugaan awal, sang ibu yang baru melahirkan anak pertamanya itu mengalami baby blues syndrome.

3. Kesalahan penggunaan tanda titik koma Kutipan berita: "Kemudian polisi datang \&Irm; menanyakan alamt rumah ibu itu.

Kesalahan: "Kemudian polisi datang \&Irm; menanyakan alamt rumah ibu itu.

Perbaikan: sesudah kata Irm seharusnya tidak menggunakan tanda titik koma. Kalimatnya berbunyi "Kemudian polisi datang \&Irm menanyakan alamt rumah ibu itu”.

4. Kesalahan penggunaan tanda titik koma
Kutipan berita: Dari \& Irm; sejumlah keterangan polisi, kata dia, anaknya yang masih bayi dibunuh menggunakan pisau dapur setelah dimandikan.

Kesalahan: Dari \& Irm; sejumlah keterangan polisi, kata dia, anaknya yang masih bayi dibunuh menggunakan pisau dapur setelah dimandikan. Perbaikan: setelah kata Irm; seharusnya tidak menggunakan tanda titik koma karena kalimatnya sudah jelas. Kalimat berbunyi "Dari \& Irm sejumlah keterangan polisi, kata dia, anaknya yang masih bayi dibunuh menggunakan pisau dapur setelah dimandikan”.

5. Kesalahan penggunaan huruf titik

Kutipan berita: Setahu kami memang ada bayi baru lahir. Tinggal di rumah mertua. Cuma kami tidak menyangka bakal setragis itu," kata Sinta (35), warga sekitar.

Kesalahan: Setahu kami memang ada bayi baru lahir. Tinggal di rumah mertua. Cuma kami tidak menyangka bakal setragis itu," kata Sinta (35), warga sekitar.

Perbaikan: setelah kata mertua tidak menggunakan tanda titik. Kalimat berbunyi "Setahu kami memang ada bayi baru lahir. Tinggal di rumah mertua cuma kami tidak menyangka bakal setragis itu," kata Sinta (35), warga sekitar".

6. Kesalahan penggunaan tanda koma

Kutipan berita: Sang ibu yang berada di rumah, dekat menusukkan pisau dapur ke tubuh bayi berusia tiga bulan itu.

Kesalahan: Sang ibu yang berada di rumah, dekat menusukkan pisau dapur ke tubuh bayi berusia tiga bulan itu.

Perbaikan: setelah kata di rumah seharusya tidak menggunakan tanda koma. Kalimat berbunyi "Sang ibu yang berada di rumah dekat menusukkan pisau dapur ke tubuh bayi berusia tiga bulan itu”.

\section{Data 5: Detiknews}

Komnas Perempuan Sebut Istri Pelaku Pembunuhan Suami Perlu Digali Akarnya.

I. Kesalahan penggunaan huruf miring

Kutipan berita: Riri menjelaskan, Komnas Perempuan selama ini menangani kasus femicida, di mana perempuan menjadi korban pembunuhan yang dilakukan oleh pasangannya.

Kesalahan: Riri menjelaskan, Komnas Perempuan selama ini menangani kasus femicida, di mana perempuan menjadi korban pembunuhan yang dilakukan oleh pasangannya.

Perbaikan: kata femicida menggunakan huruf miring merupakan bahasa asing. Kalimat berbunyi "Riri menjelaskan, Komnas Perempuan selama ini menangani kasus femicida, di mana perempuan 
menjadi korban pembunuhan yang dilakukan oleh pasangannya”.

2. Kesalahan penggunaan huruf miring

Kutipan berita: Biasanya, kasus femicida terjadi setelah ada tindakan KDRT yang cukup lama. Femicida merupakan puncak dari kekerasan terhadap perempuan,” jelas Riri.

Kesalahan: Biasanya, kasus femicida terjadi setelah ada tindakan KDRT yang cukup lama. Femicida merupakan puncak dari kekerasan terhadap perempuan," jelas Riri.

Perbaikan: Biasanya, kasus femicida terjadi setelah ada tindakan KDRT yang cukup lama. Femicida merupakan puncak dari kekerasan terhadap perempuan," jelas Riri. Kata femicida menggunakan huruf miring merupakan bahasa asing.

3. Kesalahan penggunaan huruf miring

Kutipan berita: Istri-istri ini bahkan sampai menyewa assassin alias pembunuh bayaran untuk suami.

Kesalahan: Istri-istri ini bahkan sampai menyewa assassin alias pembunuh bayaran untuk suami.

Perbaikan: Istri-istri ini bahkan sampai menyewa assassin alias pembunuh bayaran untuk suami. Kata assassin menggunakan huruf miring merupakan bahasa asing.

4. Kesalahan penggunaan tanda koma

Kutipan berita: Rupanya Aulia memiliki utang Rp IO miliar untuk usaha restran. Aulia disebut berutang dengan jaminan dua sertifikat, yakni rumah dan bengkel, milik suaminya.

Kesalahan: Rupanya Aulia memiliki utang Rp IO miliar untuk usaha restran. Aulia disebut berutang dengan jaminan dua sertifikat, yakni rumah dan bengkel, milik suaminya.

Perbaikan: dalam satu kaliamt terlalu bayak menggunakan tanda koma serti kata setelah sertifikat, dan bengkel, kalimat perbaikannya berbunyi "Rupanya Aulia memiliki utang Rp IO miliar untuk usaha restran. Aulia disebut berutang dengan jaminan dua sertifikat, yakni rumah dan bengkel, milik suaminya".

\section{Simpulan}

Berdasarkan hasil pembahasan dapat disimpulkan bahwa kesalahan berbahasa dalam teks berita online detik news dan tribun news, yakni kesalahan dari segi tanda baca dan huruf miring meliputi kesalahan penggunaan tanda hubung, penggunaan tanda titik, penggunaan huruf kapital,
Kaitannya dengan penelitian terdahulu menurut Yulianto (2016) meneliti "Kesalahan Pemakaian Ejaan dalam Tabloid "Kisah Hikmah". Hasil dari penelitiannya menunjukkan terdapat kesalahan berupa penggunaan tanda titik, tanda koma dan lainya. Sedangkan penelitian saya fokus pada kesalahan tanda baca dan huruf miring yang terdapat dalam berita online detiknews dan tribunnews.

$$
\text { Lasiratan (2019) meneliti "Analisis }
$$

Kesalahan Penggunaan Ejaan pada Teks Dialog Siswa Kelas VIIC SMP Negeri 4 Tolitoli”. Hasil dari penelitiannnya menunjukkan kesalahan ejaan pada teks dialog yang terdiri dari penggunaan huruf kapital, huruf kecil, tanda koma, tanda titik. Sedangkan dalam penelitian saya terdapat juga kesalahan tanda baca yang di sebabkan kurang cermatnya editing dalam menyusun berita.

Nurwicaksono Dwi Bayu (2018) meneliti "Analisis Kesalahan Berbahasa Indonesia pada Teks Ilmiah Mahasiswa”. Hasil penelitiannya menunjukkan dari 424 temuan kesalahan, kesalahan pemakaian huruf 183 atau 43,I6\% yang dominasi kesalahan pada pemakai huruf miring, kesalahan pada penulisan kata mencapai I45 atau setara 34,20\% dominasi kesalahan pada penulisan kata berimbuhan awalan di- dan kata depan di, kesalahan tanda baca 68. Sedangkan dalam penelitian saya terdapat II kesalahan tanda baca yang terdapat dalam berita online.

Jalal (2012) meneliti "Problematika Kesalahan Bahasa pada Penulisan Skripsi Mahasiswa Universitas Airlangga”. Hasil penelitiannya menunjukkan kesalahan berupa kesalahan ejaan yang disebabkan yang bersangkutan tidak bisa menerapkan kaidah bahasa Indonesia yang baik dan benar. Sedangkan dalam penelitian yang saya temukan berupa tanda baca dan huruf miring.

Ariana (2012) meneliti "Kesalahan Penggunaan Kajian yang Disempurnakan dalam Karya Ilmiah Dosen Unversitas Bina Darma”. Hasil penelitiannya berupa penggunaan EYD dalam artikel penulisan karya Ilmiah dosen. Kesalahan meliputi huruf miring, huruf kapital, tanda titik, tanda koma. Sedangkan dalam penelitian saya terdapat beberapa kesalahan tanda baca pada berita dua sumber berita online.

penggunaan tanda koma. Kesalahan dalam berita online ini disebabkan adanya ketidakcermatan penyunting dalam menulis berita dan tidak memahami kaidah kebahasaan dalam bahasa Indonesia. Kesalahan ejaan sering sekali terjadi dalam berita online maupun cetak hal ini disebabkan 
kurang cermat dalam menulis. Kesalahan yang terdapat dalam berita tidak banyak hanya beberapa saja. Bahkan pada berita ada juga yang penulisanya seutuhnya benar. Dengan demikian pentingnya untuk belajar bahasa Indonesia agar kemampuan terasah dengan lebih baik dan tidak ada kesalahan yang terjadi dalam sebuah penulisan.

\section{Persantunan}

Terima kasih kepada seluruh pihak yang telah memberikan dukungan dan membantu terselesaikannya artikel ini.

\section{Daftar Pustaka}

Alber. (2018). Analisis Kesalahan Penggunaan Frasa pada Tajuk Rencana Surat Kabar Kompas. Madah: Jurnal Bahasa Dan Sastra, 9(I), 55. https://doi.org/I0.31503/madah.v9iI.689

Ariana, S. (2012). Kesalahan Penggunaan Ejaan Yang Disempurnakan Dalam Karya Ilmiah Dosen Universitas Bina Darma. Jurnal Ilmiah Bina Edukai, 5(2), 53-62.

Ariani, P. (2019). Analisis Kesalahan Ejaan Dalam Karangan Siswa Pada Mata Pelajaran Bahasa Indonesia Kelas III 2 Mojoarum Kecamatan Gondang Kabupaten Tulungagung Tahun Ajaran 2018/2019. Jurnal Pena SD, 5(I), I-7.

Ariyanti, R. (2019). Analisis Kesalahan Penggunaan Huruf Kapital, Tanda Baca, dan penulisan Kata Pada Koran Mercusuar. Jurnal Bahasa Dan Sastra, 4(4), I2-28. Retrieved from http://jurnal.untad.ac.id/jurnal/index.php/BDS /article/view/I2I78/936I

Arizona, N., \& Rusmito, N. E. (2016). Kesalahan Penggunaan Ejaan Pada Skripsi Mahasiswa Fakultas Hukum Unila Dan Implikasinya. Jurnal Kata (Bahasa, Sastra, Dan Pembelajarannya), 4(3), I-IO.

Faisah, N. (2018). Analisis Kesalahan Berbahasa Indonesia Dalam Surat-Menyurat Di Kantor Kelurahan Layana Indah. Jurnal Bahasa Dan Sastra, 3(3), I-8.

Fauzi, Bastanul. Rizal, Syaiful.Rohman, F. (2019). Analisis Kesalahan Ejaan Dan Kalimat Dalam Skripsi Mahasiswa Universitas Brawijaya Sebagai Dasar Penentuan Strategi, Tujuan, Dan Bahan Ajar Mata Kuliah Bahasa Indonesia Di Universitas Brawijaya. Bahastra, 4(I), 36-4I.

Jalal, M. (20I2). Problematika Kesalahan Bahasa pada Penulisan Skripsi Mahasiswa Universitas Airlangga. Jurnal Ilmu Humaniora, I2(2), 92I04.

Kurniasari, Nia Andrianti, V., \& Isnaini, H. (2018). Analisis Kesalahan Ejaan Pada Salah Satu Judul Berita “ Isu Tka Digoreng Menjelang Pilpres ” Pada Surat Kabar Tribun Jabar Edisi 25 April 2018. Jurnal Pendidikan Bahasa Dan Sastra
Indonesia, I(4), 527-534.

Lantuba, Yanis Men, G. L. \& Y. N. (2017). Analisis Kesalahan Penggunaan Ejaan Dalam Penyusunan Rencana Pelaksanaan Pembelajaran ( Rpp ) Guru Sekolah Dasar Kecamatan Ulujadi. Bahasantodea, 5(4), I06-I2I.

Lasiratan, W. (2019). Pada Teks Dialog Siswa Kelas VIIC DI SMP NEGERI 4 Tolitoli. Jurnal Bahasa Dan Sastra, 4(3), 35-48.

Manaf, N. A. (20I3). Kesalahan kalimat dalam teks eksposisi siswa kelas $\mathrm{x}$ sma adabiah padang. Jurnal Pendidikan Bahasa Dan Sastra Indonesia, I(7), I9.

Markhamah, \& Sabardila, A. (2010). Analisis Kesalahan dan Karakteristik Bentuk Pasif. Surakarta: Jagat ABJAD.

N, D. A., Km, N., Sartika, A., Rasna, I. W., \& Sudiara, I. N. S. (20I4). Analisis Kesalahan Bahasa Indonesia Pada Esai Mahasiswa Jurusan Pendidikan Bahasa Dan Sastra Indonesia: Sebuah Kajian Ejaan, Diksi, Dan Struktur. Jurnal Pendidikan Bahasa Dan Sastra Indonesia Undiksha, 2, I-IO.

Nisa, Khoirun, I. S. (2017). Kesalahan Penggunaan Bahasa Indonesia Dalam Teks Terjemahan Mahasiswa. Basindo, I(I), I-I3.

Nisa, K. (2018). Analisis Kesalahan Berbahasa Pada Berita Dalam Media Surat Kabar Sinar Indonesia Baru. Jurnal Bindo Sastra, 2(2), 218. https://doi.org/I0.32502/jbs.v2i2.I26I

Nurwicaksono Dwi Bayu, D. A. (2018). Analisis Kesalahan Berbahasa Indoonesia Pada Teks Ilmiah Mahasiswa. Jurnal Pendidikan Bahasa Dan Sastra Indonesia, 2(2), I38-I53.

Prihantoro, E., \& Fitriani, D. R. (2015). Modalitas dalam Teks Berita Media Online. Prosiding PESAT (Psikologi, Ekonomi, Sastra, Arsitektur, \& Teknik Sipil), 6, 17-25.

Rahmawati, L. E., Kartikasari, F., \& Sukoco, Y. W. T. (20I4). Analisis Kesalahan Berbahasa pada 20 Paket Soal Ujian Nasional Bahasa Indonesia SMP 2012/20I3. Jurnal VARIDIKA, 26(2), I29I40.

https://doi.org/I0.239I7/varidika.v26i2.682

Rahmawati Nur, \& Didah, N. (20I8). Makna Leksikal Dan Gramatikal Pada Judul Berita Surat Kabar Pos Kota (Kajian Semantik). Jurnal Sasindo Unpam, 6(I), 39-54. https://doi.org/I0.IOI7/CBO978II074I532 4.004

Reza Qhadafi, M. (2018). Analisis Kesalahan Penulisan Ejaan yang Disempurnakan dalam Teks Negosiasi Siswa SMA Negeri 3 Palu. Jurnal Bahasa Dan Sastra, 3(4). Retrieved from https:/ / www.google.com/url?sa $=t \& r c t=j \& q=\&$ e src $={ }_{s} \&$ source $={ }_{\text {web } \& c d}=2 \&$ ved $=2$ ahUKEwixx $\mathrm{T}$ -

16PoAhXGfHOKHYqICIAQFjABegQIBhAB\&u $\mathrm{rl}=$ http $\% 3 \mathrm{~A} \% 2 \mathrm{~F} \% 2$ Fjurnal.untad.ac.id\%2Fjurn al\%2Findex.php\%2FBDS\%2Farticle\%2Fdownlo ad\%2FI0525\%2F8284\&usg=AOvVaw0A5UrJ 9I IxgsXcrg4kGJpx 
Salam Sucipto, Sumardi, H. (2016). Analisis Kesalahan Penggunaan Tanda Baca Tanya Dan Tanda Baca Titik Pada Teks Dialog Siswa. PedadidaktikA: Jurnal Ilmiah Pendidikan Guru Sekolah Dasar, 3(2), I68-I75.

Sari Rika Dewi, Fadhilah, M. A., \& Nucifera, P. (2019). Analisis Kesalahan Penggunaan Ejaan Bahasa Indonesia ( Ebi ) Pada Kolom Opini Surat Kabar Serambi. Jurnal Samudra Bahasa, 21, 25-3I.

Sasongko Dwi Sempu. (2018). ANALISIS Kesalahan Bahasa Pada Proposal Kegiatan Mahasiswa Un Pgri Kediri 2016-2017. Jurnal Bahasa, Seni, Dan Pengajaran, 2(I), 29-34. https://doi.org/I0.I0I7/CBO978II074I532 4.004

Septina Lisdayanti. (2019). Kesalahan Penggunaan Ejaan Pada Informasi Layanan Niaga Di Kota Bengkulu. Journal of Chemical Information and Modeling, $7(\mathrm{I})$, 27-32. https://doi.org/I0.I0I7/CBO978I I074I532 4.004

Sihobing, B. M. (2017). Pembingkaian Berita Politik Dalam Pemilihan Kepala Daerah (Analisis Framing Berita Pemilihan Walikota Pekanbaru Di Surat Kabar Tribun Pekanbaru Dan Riau Pos). Jom Fisip, 4(2), I-II. https://doi.org/I0.I0I7/CBO978I I074I532 4.004

Sutrisna, D. (2017). Analisis Kesalahan Morfologi Bahasa Indonesia Dalam Surat Kabar Radar Majalengka
Edisi I6 Dan 25 April 2016. Diglosia, I(I), I633.

Suwartini, I. (20I4). Analisis Teks Eksplanasi Pada Media Masa Melalui Pembelajaran Berbasis Masalah. Jurnal B ahastra, XXXII (I), 49-64. https://doi.org/I0.I0I7/CBO978I I074I532 4.004

Usha, P., \& Kader, N. A. (2016). Syntactic and Morphological Error Analysis in English Language among Secondary School Students of Kerala. IOSR Journal Of Humanities And Social Science (IOSR-JHSS, 2I(2), 99-I03. https://doi.org/I0.9790/0837-2I2I991063

Winata, N. T. (2019). Analisis Kesalahan Ejaan Bahasa Indonesia Dalam Media Massa Daring (Detikcom). Bahtera Indonesia; Jurnal Penelitian Bahasa Dan Sastra Indonesia, 4(2), II5-I2I. https://doi.org/I0.31943/bi.v4i2.52

Yosi, W. (2014). Tajuk Rencana Harian Kompas Dan Media Indonesia Mengupas Nasib TKI: Analisis Perbandingan Stuktur Teks. Jurnal Bahastra, XXXII(8I-I08), I-I I.

Yudha, W. (20I4). Analisis Kesalahan Berbahasadalam Karangan Bahasa Indonesia Siswa Kelas Xi Smk Negeri Rembang Kabupaten Pasuruan Tahun Pelajaran 2013/20I4. Nosi, 2(3), 254-263.

Yudha, W. (20I4). Analisis Kesalahan Berbahasadalam Karangan Bahasa Indonesia Siswa Kelas XI SMK Negeri Rembang Kabupaten Pasuruan Tahun Pelajaran 2013/20I4. Nosi, 2(3), 254- 